\title{
Repensando processos de formalização em sistemas informatizados: analisando a co-evolução entre software e práticas organizacionais
}

DOI: 10.3395/reciis.v3i2.256pt

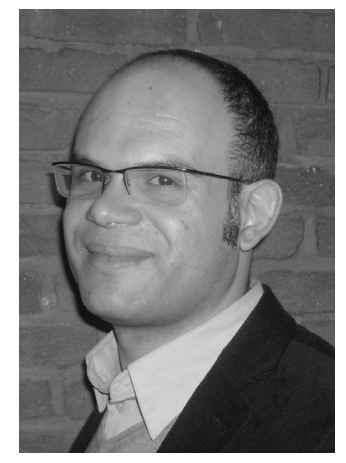

João Porto de Albuquerque

Escola de Artes, Ciências e Humanidades de São Paulo, São Paulo, Brasil jporto@gmail.com

\section{Resumo}

Sistemas informatizados são crescentemente utilizados com o objetivo de melhorar o tratamento e a integração das informações da área médica, informatizando os processos de trabalho em saúde. Torna-se necessário, assim, obter uma compreensão ampla dos imbricamentos sociotécnicos existentes no desenvolvimento e uso desses sistemas, indo além de pressupostos simplistas que atribuem unicamente à tecnologia empregada os benefícios obtidos com a informatização. Com o intuito de propiciar instrumentos efetivos para tal compreensão, este trabalho visita teorias e práticas relacionadas ao conceito de formalização no contexto do desenvolvimento de sistemas informatizados, examinando seus pressupostos e sintetizando-os num quadro de referência denominado eixo de formalização. Apoiado em recentes trabalhos na área dos estudos de Ciência, Tecnologia e Sociedade, esboça-se, então, uma perspectiva sobre processos de formalização como associação de diferentes elementos em redes sociotécnicas, as quais engendram assim um movimento de co-evolução entre software e práticas organizacionais.

\section{Palavras-chave}

informatização; formalização; práticas organizacionais; redes sociotécnicas

\section{Introdução}

Os últimos anos assistiram uma disseminação crescente do uso de Tecnologias de Informação e Comunicação (TIC) nos mais diversos setores e atividades da sociedade, incluindo o setor de saúde. A introdução de TIC para apoiar sistemas de informação na área hospitalar é comumente justificada pela necessidade de melhorar o tratamento e a integração das informações da área médica, informatizando os processos de trabalho em saúde e gerando ganhos de produtividade e qualida- de dos serviços de saúde (SAÚDE, 2004). Entretanto, embora sistemas informatizados sejam comumente tidos como os vetores de inovação causadores da transformação de organizações, o grau de eficácia desses sistemas dos depois de sua implantação nem sempre alcança as expectativas neles depositadas. Essas decepções são muitas vezes atribuídas à dificuldade, incapacidade ou resistência dos usuários em lidar com a tecnologia, em uma apreciação assimétrica segundo a qual os sucessos obtidos com o uso dos sistemas informatizados dever-se- 
iam a características intrínsecas à tecnologia, enquanto que os fracassos seriam frutos de problemas sociais "nãotécnicos" (TEIXEIRA et al., 2007; ZARAMA-VASQUEZ et al., 2008).

Pesquisas dos estudos de Ciência, Tecnologia e Sociedade $^{1}$ (CTS) das últimas décadas têm questionado essa explicação assimétrica da relação entre artefatos de tecnologia e práticas organizacionais, buscando explicar os resultados alcançados por sistemas informatizados no setor de saúde, como argumentam Zarama e Vinck (2008), não por características “técnicas" intrínsecas à tecnologia, nem pelo sistema social "não-técnico", e tampouco por uma combinação de fatores "técnicos" e "nãotécnicos". Essas pesquisas buscam uma compreensão mais ampla dos imbricamentos sociotécnicos existentes no desenvolvimento e uso de sistemas informatizados a partir de uma análise das práticas dos atores envolvidos em suas ações situadas (SUCHMAN, 2007), reconceituando os artefatos tecnológicos - e, em particular, os sistemas informatizados - como redes heterogêneas que articulam humanos e não-humanos (LATOUR, 2005). Essa visão, ampliada para abarcar ao mesmo tempo e indissociavelmente aspectos "técnicos" e "não-técnicos" em um olhar sociotécnico (CUKIERMAN et al., 2007), faz-se, portanto, essencial para uma compreensão mais aprofundada das implicações da crescente informatização dos processos organizacionais no setor de saúde.

Seguindo essa linha, o presente ensaio busca repensar o conceito de formalização, comumente utilizado no desenvolvimento de TIC para indicar o processo no qual descrições de práticas sociais são convertidas em programas de computador (software). Para tanto, a investigação se inicia com uma análise dos usos do termo formalização (Seção 2), seguida pelo exame dos pressupostos ontológicos freqüentemente assumidos em relação a práticas informais e artefatos de software, sintetizando-os em um quadro de referência denominado eixo de formalização (Seção 3). A seguir, proponho que esse quadro de referência implica em um debate aporético entre maneiras de conceber a relação entre as práticas organizacionais e o software, ora determinada por aquelas, ora por este (Seção 4). O quadro do eixo de formalização é, então, contraposto ao referencial teórico dos estudos CTS (Seção 5), servindo-nos de base para esboçar uma reconceituação dos processos de formalização que considera a formalização como associação de diferentes elementos em redes sociotécnicas, engendrando assim um movimento de co-evolução entre software e práticas organizacionais (Seção 6). Este ensaio se conclui com a apresentação de considerações finais na Seção 7.

\section{O duplo sentido do formal}

O termo formalização tem recorrente emprego no desenvolvimento de Tecnologias de Informação e Comunicação (TIC), geralmente indicando um processo no qual descrições vagas e imprecisas de procedimentos e práticas do "mundo social" são gradualmente convertidas em modelos computacionais exatos e executáveis, sendo em última instância implementados em programas de com- putador (software). Em uma leitura lógico-matemática, a formalização envolvida no processo de desenvolvimento de software consistiria em essência na expressão de procedimentos em um determinado formalismo ou linguagem formal, isto é, de acordo com uma gramática de sintaxe rigorosa e explicitamente definida ${ }^{2}$. Um software seria fundamentalmente visto como a implementação de uma seqüência finita de operações de manipulação simbólica (também chamada de algoritmo), ou seja, como um artefato formal cujo funcionamento poderia ser descrito, em sua forma mais abstrata e acabada, como uma máquina simbólica determinista ${ }^{3}$.

Em outros contextos, porém, algo é dito formal quando se enquadra em convenções ou normas estabelecidas - por oposição a informal, coloquial - como, por exemplo, um conjunto de regras escritas. Esse significado está ligado à comum distinção entre a parte formal de uma organização - isto é, suas estruturas, regras e procedimentos explicitamente definidos, geralmente por meio de documentos tais como organogramas e padrões - e o componente informal e corriqueiro das práticas organizacionais. De fato, segundo o Dicionário Houaiss da Língua Portuguesa o verbo formalizar significa: "1. criar normas, regras, modelos, procedimentos padronizados; 2. efetuar de acordo com fórmulas, regras, praxes etc.; oficializar" (HOUAISS et al., 2001). Esta segunda definição do dicionário evidencia também o caráter normativo do formal, isto é, ao se dizer que certa maneira de agir é formal, afirma-se implicitamente que esta maneira é a correta, sancionada por sua submissão às normas de um grupo social. Formalizar é, portanto, sempre também "distinguir o legal do ilegal” (BOWERS, 1992, p.243).

Ora, ainda que a formalização inerente ao processo de desenvolvimento de software e sua utilização em organizações seja freqüentemente conceituada como transformação técnica que elimina as imprecisões do mundo social, esse duplo sentido de formal implica que há sempre nesse processo dimensões que escapam ao enquadramento do software como artefato "puramente" técnico, espraiando-se em relações e práticas sociais. Para examinar essas implicações mais amplas dos processos formalização, a próxima seção parte da análise dos pressupostos freqüentemente assumidos sobre softwares e práticas organizacionais.

\section{O eixo de formalização}

Berg (1997) distingue dois discursos comuns sobre a relação entre sistemas informatizados e práticas de trabalho em organizações, que, ainda que reconhecidamente caricaturais, servir-nos-ão como um bom ponto de partida. Uma primeira posição é sustentada pelo grupo denominado por Susan Leigh Star de "formalistas ingênuos" (apud BERG, 1997, p.405). Para esse grupo, softwares são artefatos formais de processamento simbólico que possuem como qualidade intrínseca a característica de se comportarem de acordo com procedimentos lógicos precisamente especificados (i.e. algoritmos), sendo, portanto, essencialmente superiores aos vagos procedimentos informais do mundo social ${ }^{4}$. $\mathrm{O}$ modelo formal 
capturaria, assim, graças a seu maior nível de abstração e racionalidade inerentes, a essência dos elementos do mundo social por ele representados. Segundo essa visão, o processo de formalização é entendido como depuração técnica do vago ao preciso (AGRE, 1992), de forma que os problemas principais a serem enfrentados na construção do software estariam concentrados no trabalho necessário para eliminar as ambigüidades e imprecisões dos procedimentos de uma organização, representando-os mediante símbolos e definindo operações a serem executadas por artefatos formais sobre esses símbolos. Após seu desenvolvimento, um software poderia ser inserido com proveito na organização para "racionalizar" as práticas de trabalho. Por sua crença na superioridade intrínseca das estruturas lógicas formais sobre as informais, e devido à assunção de que a estrutura do mundo pode ser descrita essencialmente em termos matemáticos - ou, usando a metáfora de Galileu: o livro da natureza é escrito na linguagem da matemática -, essa posição teórica está ligada à tradição filosófica do positivismo.

Num extremo oposto encontra-se a posição teórica que denomino "salvadores do mundo da vida" (por razões que, espero, ficarão claras a seguir). Os defensores dessa posição partem da premissa de que os artefatos formais seriam nada mais do que uma versão fundamentalmente empobrecida em comparação com a riqueza do mundo empírico. Artefatos formais que modelam práticas de trabalho baseados em regras ou fórmulas, portanto, não lograriam senão oferecer um esboço grosseiramente lacunar e superficial do mundo social que representam, ocasionando inflexibilidade para a organização ao serem inseridos em situações particulares de uso. Ao funcionar de maneira inevitavelmente rígida e empobrecida, os artefatos formais, sob essa perspectiva, desumanizariam e tornariam mecânico (de-skilled) o trabalho daqueles que estiverem aprisionados em sua racionalidade instrumental, num pesadelo taylorista (BERG, 1997, p.406). Se alguma vez esses engessados artefatos alcançam certo êxito na prática, esse fato dever-se-á, para os “salvadores”, à flexibilidade e criatividade humanas para lidar com as intempéries do "mundo da vida" e assim compensar, com sua versatilidade e capacidade de interpretação, as toscas limitações dos artefatos formais.

Ainda que diametralmente opostas no valor conferido aos artefatos formais, ambas as posições acima se assentam sobre certas premissas comuns, às quais cumpre tornar explícitas. A principal suposição diz respeito às características essenciais dos artefatos formais: para as duas posições, o Formal se consitui como um domínio específico da realidade, o reino simbólico da abstração homogênea, regido por leis deterministas que podem ser precisamente e exaustivamente descritas através de formalismos matemáticos. Concordando nesse ponto, formalistas ingênuos e salvadores do mundo da vida discordam ferozmente no que diz respeito ao valor a ser atribuído a essas características de artefatos formais: para aqueles, a necessidade do mundo Formal estabelece o ideal máximo de perfeição a ser buscado, enquanto que estes a desprezam como limitação a ser transposta. O Informal, por sua vez, possui características complemen- tares às de seu par: é o reino da imprecisão do mundo concreto, da contingência e da liberdade do espírito humano. Enquanto que para os formalistas essa "bagunça" do domínio social deve ser domada e purificada ${ }^{5}$, os "salvadores" se definem como bastiões da liberdade e do gênio humano em sua luta contra a fria e mecânica racionalidade técnica.

Subjacente às duas posições acima jaz, portanto, a idéia de que Informal e Formal se referem a dois domínios disjuntos da realidade - o 'domínio social' e o 'domínio técnico’, respectivamente - que seriam essencialmente e fundamentalmente diferentes (Figura). O processo de formalização seria, portanto, entendido como um deslocamento unidimensional ao longo de um eixo que liga o domínio social ao domínio técnico. Nesse eixo, os pontos intermediários contêm formas compostas de alguns elementos formais e outros informais, permanecendo esses dois grupos da composição, todavia, sempre separados e justapostos tal qual líquidos imiscíveis. Dessa forma, à medida que se desliza no eixo em direção ao ideal de representação simbólica e execução determinista, um maior número de elementos da composição pertencerá ao domínio técnico; conseqüentemente, o nível de formalização aumenta.

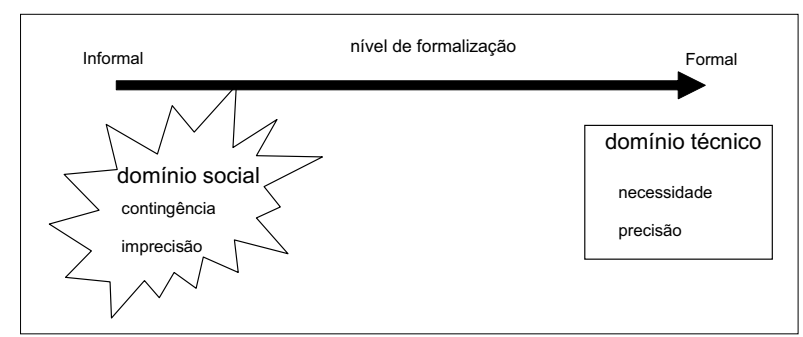

Figura - O eixo de formalização.

Colocada a questão dessa forma, o ponto fundamental de contenda se torna: o quê e quanto se deve formalizar? Para os defensores das duas caricatas posições descritas acima as respostas já existem prontas: para os primeiros se deve formalizar o máximo possível, enquanto que, para os segundos, deve-se resistir ao máximo a tentativas de formalização. Há nos últimos anos, entretanto, a crescente percepção de que essas posições entrincheiradas e extremas não são de grande serventia para lidar com as complexas interações entre artefatos formais e práticas informais. Não obstante, muito embora aguerridos extremistas como aqueles talvez tenham se tornado mais raros hoje em dia, o quadro de referência definido pelo eixo de formalização caracterizado acima continua, ainda, pautando em larga medida as decisões e debates acerca do desenvolvimento e utilização de software em organizações.

Ao invés de argumentar contra ou a favor da formalização de práticas organizacionais (ou mesmo tentar definir um grau "correto" de formalização sobre o eixo), acreditamos que a saída para os impasses descritos acima só se poderá obter mediante uma mudança do referencial ontológico subjacente a essas questões, ou seja, despedindo-nos do quadro de referência definido 
pelo eixo de formalização e buscando novas perspectivas para a análise de processos de formalização. Felizmente, é possível encontrar ecos dessa tarefa em estudos empreendidos nos últimos anos em diferentes áreas como cognição distribuída, Trabalho Colaborativo Apoiado por Computador (Computer-Supported Cooperative Work), e estudos de Ciência e Tecnologia e Sociedade. Com base nesses estudos, examinamos a seguir recursos teóricos capazes de abrir novas possibilidades para pensar a relação entre artefatos formais e práticas sociais em organizações.

\section{O software entre os determinismos técnico e social}

$\mathrm{Na}$ discussão anterior, verificamos a emergência do contraste entre, de um lado, softwares ou artefatos formais e, de outro, práticas do mundo social ou organizacional, contraste esse engendrado pelos discursos que gravitam em torno do desenvolvimento e uso de TIC - tanto dos próprios desenvolvedores como de seus críticos. Para empregar um termo comum no discurso antropológico, também utilizado por Bowker e Star (2000, p.299), esses discursos naturalizam o objeto software como artefato exclusivamente "Formal" (entendido como um domínio autocontido da realidade), tornando invisíveis as inúmeras associações de pessoas e coisas necessárias e pressupostas para permitir que TIC funcionem segundo o modelo da máquina lógica determinista, como por exemplo: os usuários "configurados" para se adequar às expectativas do software (WOOLGAR, 1991), e mesmo a imprescindível e complexa rede de energia elétrica, com seus diversos elementos humanos e materiais (HUGHES, 1983). Para ilustrar esse último ponto, àqueles que argumentam que os circuitos de um computador não passariam de artefatos lógicos que 'devido a sua natureza binária’ somente poderiam assumir os estados "0" ou "1", cabe mencionar a observação de Pirsig (1984, p.329): quando o computador está desligado ele não se encontra em nenhum dos dois estados, mas sim numa terceira possibilidade que não pode ser descrita nem por " 0 " nem por " 1 " 6 - o que evidencia a existência de pressupostos implícitos quando se pensa na 'natureza binária' do computador digital.

Visto que o artefato formal é considerado nessa visão naturalizada como um objeto com propriedades e funções específicas, fixadas no momento de sua construção e independentes de sua posterior 'aplicação' a contextos de uso particulares, essa posição corresponde, também, ao determinismo técnico. Embora poucos autores adotem explicitamente esse rótulo, o determinismo técnico é geralmente associado aos diversos trabalhos, como muitos da área técnica de software, que se assentam sobre o pressuposto de que uma tecnologia é capaz de determinar, devido a suas características intrínsecas, a maneira com a qual é utilizada por pessoas e organizações. A relação entre tecnologias e práticas organizacionais nesses trabalhos é geralmente formulada (quando isso chega a ser feito) como "impacto" causado pela tecnologia em uma organização ou na sociedade que os emprega. Assim sendo, embora os desenvolvedores de software tenham de lidar na prática com diferentes associações de heterogêneos elementos para a construção e implementação de software em organizações, cada qual com suas características singulares - realizando o que Law (1992) denomina "engenharia heterogênea" -, para a maioria dos membros da comunidade técnica de computação e informática ${ }^{7}$ o objeto software aparece naturalizado como artefato formal ou máquina lógica algorítmica, extirpado das contingências de sua criação e da natureza situada de seu significado (BOWKER et al., 2000 p. 299). Isso os deixa desprovidos de conceitos e recursos teóricos para problematizar os desafios que enfrentam na prática. Um dos objetivos deste artigo, portanto, é buscar recursos para encontrar o software não como "puro objeto técnico", mas em um estado de estranhamento que atenue os efeitos da visão naturalizada da perspectiva técnica, tornando visíveis os complexos sociotécnicos na produção e uso de softwares em contextos organizacionais. Ao enfatizar o aspecto situado e as contingências envolvidas na utilização do software, entretanto, é preciso evitar o risco de que se caia no extremo oposto. A linha de trabalhos em sociologia da tecnologia conhecida como social construtivismo, por exemplo, parte da correta premissa de que as tecnologias estão inexoravelmente ligadas às interpretações que lhes são conferidas por diferentes grupos sociais, concluindo, porém - de maneira, a nosso ver apressada, - que são essas (por vezes divergentes) interpretações é que $d e$ terminam os efeitos das tecnologias na prática e não as suas características técnicas. Como conseqüência, uma tecnologia possuiria sempre "flexibilidade interpretativa" (PINCH et al., 1987), ou seja, ela seria essencialmente uma construção social fruto das interpretações de seus usuários, ao invés de mero reflexo das capacidades da máquina (GRINT et al., 1997, p.10). O problema com essa linha de argumentação é o de continuar a operar no eixo de formalização da Figura, apenas deslocando o efeito de um software - ou, para usar um termo de Orlikowski (2000), "a tecnologia na prática" - para o pólo oposto, inserindo-o no "domínio social”. Dessa forma, troca-se o determinismo técnico - que encara o funcionamento do software apenas como a atualização de sua potência de máquina lógica algorítmica - por um determinismo social que atribui aos usuários todo o poder e autonomia para redefinir arbitrariamente o artefato técnico, o qual "sempre poderia ser ignorado, resistido ou remoldado para alcançar os objetivos que são geralmente percebidos como vinculados à sua implementação em situações particulares", conforme a contundente crítica de Kallinikos (2004, p.141). Na prática, porém, a 'flexibilidade interpretativa' é muitas vezes limitada e alguns aspectos e comportamentos de tecnologias se mostram consideravelmente reticentes aos desejos de seus usuários. Por outro lado, negar totalmente a influência de artefatos formais sobre o comportamento humano apenas nos deixa cegos ao poder gerativo que esses artefatos exercem na prática.

Para fugir dos dois extremos acima, alguns autores advogam uma posição intermediária em que a relação 
entre tecnologia e sociedade (ou entre software e organização) seja entendida como uma interação entre certas características devidas a fatores técnicos inerentes à tecnologia e outras provenientes de interpretações sociais (e.g. ROSE et al., 2005). Essa posição equivaleria, em nosso contexto, a situar as práticas organizacionais que envolvem a utilização de software em algum ponto intermediário entre os domínios técnico e social no eixo de formalização da Figura, ou seja, a definir o efeito do uso de software como a justaposição de alguns elementos "técnicos" e outros "sociais", como observamos na seção anterior. Contudo, a questão fundamental da relação entre softwares e práticas organizacionais permaneceria ainda assim sem resposta, pois como haveríamos de definir quais são as 'características inerentes à tecnologia/ software' sem cair num determinismo técnico essencialista, e, simetricamente, como definiríamos aquelas 'características emergentes do mundo social/organização' sem resvalar num determinismo social reducionista?

\section{Repensando a ontologia do software}

A problemática discutida na seção anterior é similar à controvérsia sobre o status de fatos científicos entre realismo e construtivismo social nos estudos de ciência (sumariamente: os fatos científicos são descobertos na natureza ou inventados pelo homem?). Rouse (2002) argumenta que esse impasse advém da premissa implicitamente assumida por ambas as posições do debate de que natureza e sociedade constituem dois componentes estanques e autocontidos do mundo, os quais "interagem". O pressuposto básico aqui é o que Bruno Latour denomina "constituição moderna", isto é, uma separação ontológica implicitamente assumida entre Natureza versus Cultura ou Objeto versus Sujeito - ou ainda, Tecnologia versus Sociedade -, a qual Latour (1993) caracteriza como típica da modernidade. Essa assunção básica é comparada por Rouse (2002, p.63) a vampiros, mortos-vivos que continuam a assombrar nossos conceitos e interpretações de natureza, cultura e ciência. Assim, como saída para o impasse Rouse aponta para diversos trabalhos recentes que partem da negação radical da premissa que dicotomiza Natureza/Sociedade (enfiando definitivamente uma estaca no coração desse vampiro), para considerar o mundo como um "campo complexo de práticas materiais-discursivas” (ROUSE, 2002, p.77). Logo, ao olhar para essas práticas materiaisdiscursivas, torna-se possível transcender divisões essencialistas a priori entre natureza e sociedade, encarando essas últimas como o resultado da estabilização de um conjunto de práticas. Essa perspectiva é subsumida por Rouse sob a rubrica pós-construtivismo (ROUSE, 2002, p.69), à qual Latour (2005, p.88ss.) prefere denominar simplesmente construtivismo, sem o qualificador "social" que preservaria a dicotomia (ver a respeito também Barad 2003 e Wehling 2006).

Seguindo a linha desses trabalhos, concluímos que a questão colocada acima entre determinismo social e determinismo técnico não pode ser respondida de maneira produtiva, pois se assenta sobre a premissa implícita do eixo da formalização caracterizado na seção anterior, insistindo na oposição dicotômica a priori entre o software como artefato técnico a-contextual de um lado, e os contextos e situações particulares de sua utilização, de outro ${ }^{8}$, ou seja, incorporando a dicotomia Natureza versus Sociedade no par de opostos Formal versus Informal e tomando-os como grandes categorias incomensuráveis e essencialmente diferentes entre si. A partir dessa premissa, os efeitos do uso de software, um típico exemplo de um híbrido entre os 'domínios social e técnico', são entendidos como uma mistura de duas formas puras (LATOUR, 1993, p.78), a qual deve ser separada para que se possa discernir o que veio do sujeito - isto é, do domínio social da organização usuária - daquilo que é oriundo do objeto - ou do domínio técnico: da "natureza" do software. Assim, mesmo as posições mais moderadas que procuram fugir dos extremados determinismos técnico ou social acima descritos mantêm, todavia, a crença no abismo ontológico entre os domínios técnico e social, impedindo que se encare os processos de construção e uso de software em toda sua densa complexidade, e conduzindo ao aporético debate sobre os efeitos provenientes da "natureza" do software e aqueles oriundos das interpretações de atores sociais.

Para examinar essa problemática de forma produtiva, portanto, devemos abandonar o quadro de referência definido pelo eixo de formalização, rejeitando a dicotomia essencialista Formal/Informal e redefinindo o status ontológico ${ }^{9}$ de softwares e, simultaneamente, das práticas organizacionais de sua utilização, de forma a encará-los não como formas puras advindas respectivamente dos domínios técnico e social, nem como um agregado de elementos "puros" desses dois domínios. Assim, nosso ponto de partida será o de analisar um software sempre dentro de suas práticas de construção e utilização, como um híbrido ao mesmo tempo formal e informal, ou como diz Latour (1993, p.51ss.), um quase-objeto, quasesujeito, isto é, um artefato sociotécnico localizado fora do eixo de formalização da Figura, entre e abaixo dos dois pólos. O software se torna, assim, um mediador híbrido informal-formal de ontologia variável (LATOUR, 1993, p.85), isto é, os adjetivos técnico/social e formal/informal não são vistos como categorias essenciais capazes de nos fornecer explicações prontas sobre os efeitos de software, mas como o resultado da estabilização das práticas de desenvolvimento e utilização de artefatos - resultados para os quais devemos fornecer explicações.

Como proposto por Pickering (1995), essa visão corresponde ao movimento de uma perspectiva representacionista para um idioma performativo, o que implica o afastamento de uma visão de artefatos técnicos (software) como meras representações empobrecidas do mundo social em favor da consideração dos artefatos e de suas propriedades (e.g. rigidez, formalidade, durabilidade, determinismo etc.) como resultados continuamente produzidos por meio da performação ${ }^{10}$ de práticas materiais-discursivas. Assim, a forma, o significado e as propriedades de um software não são características determinadas a priori, mas resultados dos processos de negociação entre todos os atores (humanos e não-huma- 
nos) envolvidos em seu desenvolvimento e uso, devendo ser vistos como conquistas precárias (LAW 1992) que necessitam ser continuamente confirmadas nas práticas. Se por um lado os artefatos de software produzidos inscrevem intenções, prescrições de formas organizacionais, interesses e visões de mundo - colaborando assim para configurar o espaço social em que são empregados -; por outro lado, as práticas materiais-discursivas no contexto de utilização associam os softwares com elementos diferentes daqueles originalmente previstos - alterando assim o próprio sentido e o significado a eles atribuídos (AKRICH, 1992).

\section{Formalização como prática multidimensional de associação}

Repensar a ontologia do software como fizemos acima significa, também, abandonar a visão do processo de formalização como um movimento unidimensional ao longo do eixo da Figura, adicionando a esse movimento a consideração de outras dimensões envolvidas nas práticas de construção e uso de software. O processo multidimensional de formalização engendra, portanto, a produção simultânea de artefatos formais e de práticas organizacionais (formais e informais), num movimento de co-definição mútua que Bowker e Star (2000, p.82) denominam convergência e que, animado pelo mesmo espírito, prefiro chamar de co-evolução de softwares e práticas organizacionais, estas incluindo não apenas as práticas da organização usuária do software, mas também aquelas de seus desenvolvedores.

Nessa perspectiva, podemos encarar o eixo de formalização da Figura como a projeção unidimensional de processos multidimensionais de formalização. A categoria Formal - ligada, como vimos acima, no contexto de desenvolvimento de software ao modelo da máquina lógica algorítmica - consiste, portanto, no elemento que define essa projeção unidimensional, sendo esta um resultado da estabilização das práticas profissionais na área de computação e de seu contingente processo histórico de constituição, com fortes vínculos tanto com o mundo polarizado e militarizado da guerra fria (EDWARDS, 2000), como também com o estilo de pensamento moderno (TEIXEIRA, 2006). Entretanto, o que Suchman afirma sobre um martelo vale também para um software:

"Embora a materialidade durável do martelo permita a afirmação de que ele existe antes e depois dos momentos de seu uso, é não obstante claro que seu status como um martelo depende de sua incorporação dentro de práticas de alguma forma de carpintaria." (SUCHMAN, 2007, p.21).

Apesar do software não possuir a evidente "materialidade durável” de um martelo, a afirmação de Suchman pode ser ainda assim transposta a nosso contexto: malgrado a 'durável característica' de um software se comportar como máquina algorítmica de processamento simbólico ${ }^{11}$, o status de uma TIC como artefato formal depende de sua incorporação dentro de práticas de formalização em seu processo de desenvolvimento. Dessa forma, não se trata de negar categoricamente o caráter algorítmico ou formal de um software, mas sim de reconhecer a rede de elementos heterogêneos que necessita ser urdida - i.e. associando pessoas, conceitos, práticas profissionais de programação e teste, infra-estrutura de componentes materiais, procedimentos organizacionais etc. - para que um software seja performado segundo o modelo da máquina lógica determinista. O processo de formalização entendido em sua complexa multidimensionalidade consiste, portanto, no estabelecimento de uma rede heterogênea de pessoas e coisas em torno do artefato software, a qual tem por efeito real tanto a performance do software dentro de práticas organizacionais como a projeção, sobre o eixo de formalização, dessas práticas como elementos do "mundo social" e do software como máquina determinista no "domínio técnico". Esses dois momentos - a saber: o estabelecimento da rede heterogênea em torno do software e sua projeção no eixo de formalização - correspondem ao que Latour (1993, p.80ss.) denomina "multiplicação de híbridos" e "purificação", permitindo que se possa, no discurso profissional em computação e informática, falar de softwares como "puros" artefatos formais (i.e. purificados), enquanto que a prática de produção e uso de software atue na realidade associando complexas redes heterogêneas (i.e. proliferando híbridos).

\section{Considerações finais}

O presente ensaio procurou examinar o conceito de formalização no contexto de desenvolvimento de sistemas informatizados e de seu uso em organizações. À luz de trabalhos recentes em CTS, verificamos como o quadro de referência do eixo de formalização está implícito em alguns dos recentes debates acerca do efeito de software em organizações de saúde, propondo que a saída para os impasses entre determinismo social e técnico deve ser procurada fora desse quadro. Para tanto, esboçou-se uma compreensão do processo de formalização relacionado ao software como uma prática multidimensional de associação de elementos heterogêneos, resultando em um movimento de co-evolução entre o software e práticas organizacionais.

Essa compreensão ampliada torna visíveis dimensões que não são comumente tematizadas nos discursos das áreas técnicas em informática, mas geralmente relegadas a segundo plano e tratadas como indesejáveis interferências. Isso faz com que essas dimensões sejam também negligenciadas em diversos projetos de sistemas informatizados na área de saúde que se apóiam numa estreita visão tecnicista sobre a informação e a informática em saúde (cf. Moraes \& Gómez 2007).

Uma das importantes dimensões de processos de formalização assim descortinadas está ligada ao caráter "oficializador" de artefatos formais mencionado acima (Seção 2): a produção de software e sua incorporação em práticas organizacionais trazem consigo a "formalização" de certas práticas, no sentido de torná-las, senão oficiais e sancionadas, ao menos preferenciais e facilitadas ${ }^{12}$. Ao tornar visíveis essas associações, portanto, espero contribuir para a obtenção de recursos analíticos que 
viabilizem não apenas uma apreciação crítica das práticas de formalização em contextos organizacionais da área de saúde, mas que sirvam também à intervenção prática no sentido de construir sistemas informatizados que contribuem efetivamente para a qualidade dos serviços de saúde, levando em consideração os desdobramentos sociotécnicos de seu desenvolvimento e utilização.

\section{Agradecimentos}

Ao Prof. Dr. Arno Rolf da Universidade de Hamburgo (Alemanha) por seu apoio e incentivo, a Edouard Simon e a todos os membros da rede Mikropolis pelas frutíferas discussões que muito contribuíram para o desenvolvimento das idéias contidas neste artigo, e à Fundação Alexander von Humboldt pelo essencial apoio financeiro provido.

\section{Notas}

1. Os estudos de Ciência, Tecnologia e Sociedade (CTS) são conhecidos na língua inglesa como Science and Technology Studies (STS) e apresentados sinteticamente em (Hackett et al. 2007). Para os trabalhos de maior relevância para o presente artigo ver, por exemplo: Akrich (1992), Callon (1986), Latour (1993, 1999, 2000, 2005), Law (1992); Law \& Hassard (1999). Para uma síntese de diferentes linhas de pensamento acerca das relações entre tecnologia, inovação e sociedade ver Machado (2006).

2. Há, na realidade, diversos tipos de linguagem formal, como definidos e hierarquizados pelo lingüista Noam Chomsky (1956).

3. De fato, o modelo matemático conhecido como máquina de Turing (ver Turing 1936) tornou-se o paradigma de computação par excellence, embora, como afirma (Schinzel 2004), modelos alternativos de computação trazidos por inovações mais recentes, como algoritmos genéticos e pela computação quântica, possam desafiar essa posição central conferida ao processamento algorítmico de símbolos.

4. Embora uma grande parte dos trabalhos técnicos na área de software ainda se enquadre nessa caracterização, na realidade é possível refina-la um pouco mais e discernir, como o faz Eden (2007), diferentes paradigmas dentro da área de computação, cada um com um diferente status ontológico para o artefato software. Numa linha mais sociológica, MacKenzie (2001, p. 299 ss.) apresenta uma ótima discussão dos diferentes significados do termo "prova" em diferentes subcomunidades da área de computação, constituindo o que ele denomina "comunidades de prova".

5. Sobre o conceito de purificação nesse contexto ver (Latour 1993) e a discussão na Seção 4.

6. Pirsig evoca a tradição zen-budista japonesa ao dizer que o circuito desligado se encontra num estado " $M u$ ", palavra utilizada pelos mestres zen para indicar que a pergunta foi mal formulada e por isso não pode ser respondida nem com "sim" nem "não", significando algo como "retire a pergunta” (Pirsig 1984, p. 329).
7. Existem, como sempre, notáveis exceções que já contam com uma longa tradição, por exemplo, na comunidade européia na área de computação - ver a respeito (Porto de Albuquerque 2007) - e com uma crescente representação na comunidade acadêmica brasileira (Cukierman et al. 2007).

8. Note que, na segunda edição de seu clássico Plans and situated action, Suchman (2007, p. 21) nota, com admirável honestidade intelectual, que a sugestão feita na primeira edição de que artefatos formais (planos, no caso) estão de alguma forma fora da ação teve o efeito colateral de reforçar a dicotomia entre plano e execução que se estava justamente querendo questionar.

9. Sobre os questionamentos ontológicos propostos por trabalhos recentes em estudos CTS ver (Mol 2007).

10. Performar é o neologismo que emprego para captar a idéia do verbo inglês enact como usado em trabalhos CTS, seguindo o termo escolhido por Gonçalo Praça na tradução do artigo de $\mathrm{Mol}$ (2007).

11. Como nos lembra Law (1996), na perspectiva relacional dos estudos CTS mesmo o conceito de "materialidade durável” de um artefato pode ser posto à prova quando a estabilidade das relações que nos permitem constatar essa durabilidade muda, e então o próprio status do artefato enquanto tal se altera.

12. Nesse sentido é de especial interesse o conceito de inscrição proposto por Akrich (1992). Para um exemplo no contexto de modelagem de processos de negócio ver (Porto de Albuquerque \& Christ 2007).

\section{Referências bibliográficas}

AGRE, P.E. Formalization as social project. Quarterly Newsletter of the Laboratory of Comparative $\mathrm{Hu}$ man Cognition, v.14, n.1, p.25-27, 1992.

AKRICH, M. The de-scription of technical objects. In: BIJKER, W.; LAW, J.(Ed.). Shaping technology:building society. Cambridge, London: The MIT Press; 1992. p.205-24.

BARAD, K. Posthumanist performativity: toward an understanding of how matter comes to matter. Signs, v.28, p.801-31, 2003. [doi: 10.1086/345321].

BERG, M. Of forms, containers, and the electronic medical record: some tools for a sociology of the formal. Science, Technology \& Human Values, v.22, n.4, p.403433, 1997. [doi: 10.1177/016224399702200401].

BOWERS, J. The politics of formalism. In: LEA, M. (Ed.). Contexts of computer-mediated communication. New York: Harvester Wheatsheaf, 1992. p.233-61.

BOWKER, G. C.; STAR, S. L. Sorting things out: classification and its consequences. Cambridge, MA: MIT Press, 2000.

CALLON, M. Some elements of a sociology of translation: domestication of the scallops and the fishermen of St. Brieuc Bay. In: LAW, J. (Ed.). Power, action and 
belief: a new sociology of knowledge. London: Routledge, 1986. p.196-223.

CHOMSKY, N. Three models for the description of language. IRE Transactions on Information Theory, v.2, p.113-124, 1956.

CUKIERMAN, H. et al. Guest editor's introduction: the challenge of a sociotechnical perspective to software engineering. Scientia, v.18, n.1, p.4-6, 2007.

EDEN, A.H. Three paradigms in computer science. Minds and Machines, v. 17, n.2, p.135-167, 2007. [doi: 10.1007/s 1 1023-007-9060-8].

EDWARDS, P. The closed world. Cambridge, MA: The MIT Press, 2000.

GRINT, K.; WOOLGAR, S. The machine at work. Cambridge: Polity Press, 1997.

HACKETT, E.J. et al. The handbook of science and technology studies. 3th. ed. Cambridge, MA: MIT Press, 2007.

HOUAISS, A.; VILLAR, M.S. Dicionário houaiss da língua portuguesa. Rio de Janeiro: Objetiva, 2001.

HUGHES, T.P. Networks of power: electrification in western society, 1880-1930. Baltimore: Johns Hopkins University Press, 1983.

KALLINIKOS, J. Farewell to Constructivism: technology and context-embedded action. In: AVGEROU, C.; CIBORRA, C.; LAND, F. (Ed.). The social study of information and communication technologies. Oxford, UK: Oxford University Press, 2004. p.140-161.

LATOUR, B. We have never been modern. Cambridge, MA: Harvard University Press, 1993.

LATOUR, B. Pandora's hope: essays on the reality of science studies. Cambridge, MA: Harvard University Press, 1999.

LATOUR, B. Ciência em ação: como seguir cientistas e engenheiros sociedade afora. São Paulo: Editora Unesp, 2000 .

LATOUR, B. Reassembling the social: an introduction to actor-network theory. Oxford: Oxford University Press, 2005.

LAW, J. Notes on the theory of the actor-network: ordering, strategy and heterogeneity. Systems Practice, v.5, n.4, p.379-393, 1992. [doi: 10.1007/BF01059830].

LAW, J. Organizing modernity. London: 1996.

LAW, J.; HASSARD, J. Actor network theory and after. Oxford: Blackwell; Keele: Sociological Review, 1999.

MACHADO, C.J.S. As relações entre tecnologia, inovação e sociedade. DataGramaZero, v.7, n.1, 2006.

MACKENZIE, D. Mechanizing proof: computing, risk, and trust. Cambridge, MA: MIT Press, 2001.

MINISTÉRIO DA SAÚDE. Política nacional de informação e informática em saúde: proposta versão
2.0. Brasília: Ministério da Saúde, 2004. Disponível em: <http://bvsms.saude.gov.br/bvs/publicacoes/Politi calnformacaoSaude29_03_2004.pdf $>$. Acesso em: 30 abr. 2009.

MOL, A. Política ontológica. Algumas idéias e várias perguntas. In: NUNES, J. A.; ROQUE, R. (Ed.). Objectos impuros: experiências em estudos sociais da ciência. Porto: Edições Afrontamento, 2007.

MORAES, I.H.S.; GÓMEZ, M.N.G. Informação e informática em saúde: caleidoscópio contemporâneo da saúde. Ciência \& Saúde Coletiva, v. 12, n.3, p.553-565, 2007. [doi: 10.1590/S1413-81232007000300002].

ORLIKOWSKI, W.J. Using technology and constituting structures: a practice lens for studying technology in organizations. Organization Science, v. 1 1, n.4, p.404428, 2000. [doi: 10.1287/orsc. 1 1.4.404.14600].

PINCH, T.J.; BIJKER, W.E. The social construction of facts and artefacts: or how the sociology of science and sociology of technology might benefit each other. In: BIJKER, W.; HUGHES, P.; PINCHT, T. (Ed.). The social construction of technological systems. Cambridge: The MIT Press, 1987.

PIRSIG, R.M. Zen and the art of motorcycle maintenance. New York: Bantam Books, 1984.

PORTO DE ALBUQUERQUE, J. Aspectos sociotécnicos da computação: contextualizando o desenvolvimento de sistemas de computação com o modelo. Mikropolis, v.14, p.181-197, 2007.

PORTO DE ALBUQUERQUE, J.; CHRIST, M. Formal models, flexible processes? Lessons from a socio-technical analysis of business process modelling. Scientia, v.18, n.1, p.14-22, 2007.

ROSE, J.; JONES, M. The double dance of agency: a socio-theoretic accounts of how humans and machines interact. Signs and Actions, v.1, n.1, p.19-37, 2005.

ROUSE, J. Vampires: social constructivism, realism, and other philosophical undead. History and Theory, v.41, p.60-78, 2002. [doi: 10.1111/1468-2303.00191].

SCHINZEL, B. Computer science between symbolic representation and open construction. Lecture Notes on Computer Science, v.3075, p.59-76, 2004. [doi: 10.1007/b98383].

SUCHMAN, L. Human-machine reconfigurations: plans and situated actions. 2th. ed. New York, NY: Cambridge University Press, 2007.

TEIXEIRA, C. Algumas observações sobre os vínculos entre a engenharia de software e o pensamento moderno. In: WORKSHOP UM OLHAR SOCIOTÉCNICO SOBRE A ENGENHARIA DE SOFTWARE, 2., 2006, Vila Velha. Anais... Rio de Janeiro: PESC/COPPE UFRJ, 2006.

TEIXEIRA, C.; CUKIERMAN, H.L. Why do software process improvement projects fail? Scientia, v.18, n.1, p.24-32, 2007. 
TURING, A.M. On computable numbers, with an application to the Entscheidungsproblem. Proceedings of the London Mathematical Society, v.2, n.42, p.230265, 1936.

WEHLING, P. The situated materiality of scientific practices: postconstructivism - a new theoretical perspective in science studies? Science Technology Innovation Studies, n.1, p.81-100, 2006. Special Issue.
WOOLGAR, S. Configuring the user: the case of usability trials. In: LAW, J. (Ed.). A sociology of monsters: essays on power, technology and domination. London: Routledge, 1991.

ZARAMA-VASQUEZ, G.; VINCK, D. Por que a informatização funciona? Estratégias de compensação dos atores no caso da prescrição médica. RECIIS, v.2, n.1, p.19-28, 2008. [doi: 10.3395/reciis.v2il.159pt].

\section{Sobre o autor}

\section{João Porto de Albuquerque}

Professor em Sistemas da Informação da Escola de Artes, Ciências e Humanidades de São Paulo (EACH/USP). É Research Fellow da Fundação Alexander von Humboldt (Alemanha) e atual coordenador do grupo de pesquisa Gestão de Sistemas de Informação da EACH/USP. Suas pesquisas enfocam os aspectos sociotécnicos de Sistemas de Informação, buscando entender os movimentos de co-produção de tecnologia, formas organizacionais, sociedade e comportamentos humanos, em diálogo com os estudos de Ciência, Tecnologia e Sociedade. Tem publicado recentemente The Challenge of Transdisciplinarity in Information Systems Research: Towards an Integrative Platform (in: Information Systems Research Methods, Epistemology and Applications, IGI, Hershey), Notwendige und vorläufige Formalisierungslücken in Organisationen (in Digitalisierung der Arbeitswelt, VS Verlag, Wiesbaden) e Aspectos sociotécnicos da computação: contextualizando o desenvolvimento de sistemas de computação com o modelo Mikropolis (Revista de Informática Teórica e Aplicada). 